\title{
Yield of a second screening colonoscopy 10 years after an initial negative examination in average risk subjects
}

\author{
Prasanna L. Ponugoti, M.D. \\ Douglas K. Rex, M.D.
}

Indiana University School of Medicine, Division of Gastroenterology and Hepatology Indianapolis, IN

Address correspondence and reprint requests to:

Douglas K. Rex

550 N. University Blvd, Suite 4100

Indianapolis, IN 46202

Phone: 317-948-8741

Fax: 917-944-5449

Email: drex@iupui.edu

This work was supported by a gift to the Indiana University Foundation in the name of Douglas K Rex by Scott and Kay Schurz of Bloomington Indiana and their children

This is the author's manuscript of the article published in final edited form as:

Ponugoti, P. L., \& Rex, D. K. (2017). Yield of a second screening colonoscopy 10 years after an initial negative examination in average-risk individuals. Gastrointestinal Endoscopy, 85(1), 221-224. https://doi.org/10.1016/j.gie.2016.05.024 
Abstract:

Background: Current guidelines recommend screening colonoscopy at 10 year intervals in average risk individuals who had baseline screening colonoscopy (no polyps or only hyperplastic polyps $\leq 5 \mathrm{~mm}$ in the recto-sigmoid colon), but the yield of repeat screening at 10 years is unknown.

Aim: Describe the yield of second screening colonoscopy in average risk individuals performed at least 8 years after a first screening colonoscopy had shown no polyps or only distal hyperplastic polyps $\leq 5 \mathrm{~mm}$ in size.

Methods: Review of a database for colonoscopies performed at Indiana University Hospital between January 1999 and November 2015.

Results: A total of 4,463 individuals underwent screening colonoscopy between January 1999 and July 2007, of which, 1,566 individuals had no polyps and 334 individuals had only distal hyperplastic polyps $\leq 5 \mathrm{~mm} ; 378$ individuals (58.4\% female) had follow up screening at least 8 years after the baseline screening exam with a mean interval of $9.74(+/-1.2)$ years (range 8 to 15 years). Mean age at baseline screening exam was 56.7 (+/- 5.5) years and at follow-up screening exam was $66.4(+/-5.6)$ years. At the second screen there were 224 patients (59.3\%) with at least 1 polyp, including 144 (38.1\%) with at least 1 conventional adenoma. The adenoma detection rate (ADR) at the second screen exam was 36.1\% and 56.8\% in the groups with no polyp at baseline and with only distal hyperplastic polyps respectively. There were 15 advanced neoplasms in 13 individuals (3.4\%), of which 12 lesions were proximal to the sigmoid colon. There were no cancers at follow-up.

Conclusion: Among individuals age $\geq 50$ years with normal baseline screening colonoscopies, the incidence of advanced lesions at a second screening colonoscopy at least 8 years later was 
comparable to that in baseline screening studies. Our findings support current recommendations for screening at 10 year intervals in average risk individuals. 
Introduction:

Screening colonoscopy is recommended in all guidelines at 10 -year intervals in average risk subjects ${ }^{1-3}$. Previous reports have described the yield of a second colonoscopy 5 years after an initial negative examination in average risk persons ${ }^{4,5}$. The yield for advanced adenomas at 5 years is low, supporting an interval longer than 5 years ${ }^{5}$. Case-control studies suggest that patients are protected for 20 years or longer after a negative colonoscopy ${ }^{6}$. A negative colonoscopy may be the single strongest predictor of protection from colorectal cancer.

In this report, we describe the yield of a second screening colonoscopy in 378 average risk persons. All of the study subjects had either no polyps or only distal (recto-sigmoid colon) hyperplastic polyps $\leq 5 \mathrm{~mm}$ in size at an initial screening examination at age 50 or older. All returned in routine clinical practice at least 8 years later for a second examination while still asymptomatic.

Materials and Methods

We reviewed a prospectively maintained quality database for colonoscopies at Indiana University Hospital and its affiliated outpatient endoscopy units since 1999. Permission to review the database was granted by the Institutional Review Board at Indiana University Health on September 29, 2015. Eligible subjects were at least 50 years of age at their baseline examination, had no personal or family history of colorectal cancer, no personal history of colorectal polyps, no history of inflammatory bowel disease, and were asymptomatic. All had "screening" listed as their indication for both the initial and second examination, and had no 
colorectal polyps or only distal colon hyperplastic polyps $\leq 5 \mathrm{~mm}$ in size identified during the baseline colonoscopy. Subjects had a complete examination to the cecum with the bowel preparation listed as adequate, good or excellent.

Subjects underwent their initial screening examination between January 1999 and July 2007 and the follow up screening examination between January 2007 and November 2015. All examinations were performed by attending gastroenterologists. A total of 23 attending gastroenterologists performed the follow-up examinations. Gastroenterology fellows participated in some examinations, but withdrawals were supervised in all cases by attendings.

Conventional adenomas included tubular, tubulovillous and villous adenomas, and were characterized as having low-grade or high-grade dysplasia. Advanced conventional adenomas were those with villous elements, high-grade dysplasia, or size $\geq 10 \mathrm{~mm}$. Serrated class lesions included hyperplastic polyps and sessile serrated polyps (SSP; synonymous with sessile serrated adenoma). Advanced conventional adenomas and SSPs $\geq 10 \mathrm{~mm}$ in size or with cytological dysplasia were considered advanced neoplasms.

The chi-square test was used to compare gender, incidence of any polyp, adenoma, adenomas in males, and adenomas in females between the groups without and with distal colon hyperplastic polyps at baseline colonoscopy. The two-sample t-test was used to compare age and interval between examinations and Fishers Exact test was used to compare the incidence of any advanced adenomas between these groups.

Results 
A total of 4,463 subjects underwent screening colonoscopy between January 1999 and July 2007, of which, 1,566 (35.1\%) subjects had no colorectal polyps and 334 (7.5\%) subjects had only distal colon (rectum and/or sigmoid) hyperplastic polyps $\leq 5 \mathrm{~mm}$. There were 341 subjects with no colorectal polyps and 37 who had only distal diminutive colorectal polyps at baseline who had follow up screening colonoscopy at our institution at least 8 years after baseline screening. The subjects who repeated a screening colonoscopy included 221 women who had mean age $57.3(+/-5.5)$ years at the baseline examination, and 157 men with mean age $55.5(+/-5.7)$ years (Table 1). The overall mean age was $56.7(+/-5.5)$ years (range 50-71 years) at the baseline examination.

At the second examination, the mean age was $66.4(+/-5.6)$ years (range 58-81 years). The mean interval between examinations was $9.74(+/-1.2)$ years (range 8.0-15.0 years). Additional demographic data on the study population is not available from the database. Among those who completed second screening colonoscopies, 74 subjects had follow-up at 8 years, 52 subjects at 9 years, 188 subjects at 10 years, 36 subjects at 11 years, and 28 subjects at 12 to 15 years. (Table 2).

The adenoma detection rate (ADR) at the second screening examination was $36.1 \%$ in subjects with no baseline polyps and was higher at 56.8\% in subjects with distal colon hyperplastic polyps at the baseline examination ( $\mathrm{p}=.014$ ), and the difference in ADR reached significance in women but was only a trend in men (Table 1). At the second screening examination, a total of 268 conventional adenomas (adenomas per colonoscopy or APC of 0.78 ) were detected in 
subjects with no polyps at baseline and 37 conventional adenomas (APC 1.0) in subjects with hyperplastic polyps at baseline (Table 1). The incidence of advanced neoplasms overall was $3.4 \%$, including $3.2 \%$ in the group with no polyps at baseline and $5.4 \%$ in the group with only hyperplastic polyps at baseline $(\mathrm{p}=0.37)$.

Among the 252 patients with at least 10 years between examinations, the ADR was 39.6\%, APC was 0.87 , and the rate of advanced neoplasms was $3.6 \%$.

There were 13 individuals (8 females) with 15 advanced neoplasms at the second examination, of which 12 were proximal to the sigmoid (Table3). Nine patients had only advanced conventional adenomas, 3 had only advanced serrated class lesions, and one had both. All polyps detected at the second examination were successfully resected endoscopically.

\section{Discussion}

In this study, we report our initial experience with performing screening colonoscopies at least 8 years after an initial negative examination in average-risk persons. The overall adenoma detection rate (ADR) at the second examination was substantial at 38.1\%, which may partly reflect the mean age at the second examination of 66 years in these groups, which is higher than the mean age of essentially all previous screening colonoscopy studies examining the yield of the first time examinations in average-risk persons ${ }^{7-10}$. The high ADR may also reflect improved methods of bowel preparation, improved colonoscope imaging, and improved awareness of the importance of ADR since the baseline examination were performed. In any case, none of these 
asymptomatic individuals had cancer, and the yield of advanced lesions was 3.4\%, which is comparable to the rate of first time screening examinations ${ }^{7-10}$.

Our study has several limitations. First, patients were not systematically referred for a second examination. Thus, the subjects who presented for a second examination may have had a greater interest in maintaining good health behaviors than the general population, which might lower their risk of incident neoplasia. Next, patients who had a second colonoscopy for symptoms before a 10 year screening was due were not included. We arbitrarily included patients with an interval between examinations of $>8$ and $<10$ years, since our experience is that a significant number of patients who were instructed to wait 10 years actually present a year or two early, perhaps because of their own or their physician’s concerns about waiting until 10 years, or perhaps in some instances they lost track of the interval. Our system is open access, and we did not block these patients from undergoing the second screen early. We included these patients in this report because we suspect other's experience is similar to ours, and because the yield of a second screen in the 8-10 year interval has not been previously described. Our results generally support encouraging asymptomatic patients to wait the full 10 years between examinations.

Our data support a screening interval for average risk individuals of at least 10 years in patients with high quality baseline examinations ${ }^{2}$. The high overall ADR of $38.1 \%$ should not be considered a rationale to perform screening earlier than 10 years, since the overwhelming majority of lesions detected were diminutive and non-advanced lesions with a very low potential for harm. Additional data are needed to know whether longer intervals than 10 years are appropriate for selected portions of the average risk population, such as nonsmokers or persons 
examined by colonoscopists with high adenoma detection rates. Our data suggest the ADR targets used for first-time screening colonoscopies may be appropriate for second examinations also. Also, because $80 \%$ of the advanced lesions detected at the second screen were proximal to the sigmoid colon, our results support using colonoscopy rather than sigmoidoscopy for the second screening.

In summary, this is the first report of the yield of a second screening examination approximately 10 years after an initial negative examination in average-risk persons. We expect this result will stimulate others to examine their experience in this regard, and a larger experience will provide an accurate picture of the yield of a second examination, and whether subsets of individuals with an initial negative examination can undergo a second screening colonoscopy at an interval longer than 10 years. 
Table 1: Demographics, yield and polyp histology at second screening

\begin{tabular}{|lccc|}
\hline & $\begin{array}{c}\text { Subjects without } \\
\text { polyps at baseline } \\
\text { exam }\end{array}$ & $\begin{array}{c}\text { Subjects with } \\
\text { distal } \\
\text { hyperplastic } \\
\text { polyps at } \\
\text { baseline exam } \\
\text { Number }\end{array}$ & p-value \\
Male & $\begin{array}{c}\text { Number } \\
\text { Female }\end{array}$ & $143(41.9 \%)$ & $14(37.8 \%)$ \\
Mean age at second screening colonoscopy (range) & $198(58.1 \%)$ & $23(62.2 \%)$ & \\
Mean interval years (range) & $66.4(58-81)$ & $66.4(58-81)$ & 0.97 \\
Yield at second screening colonoscopy & $9.8(8-15)$ & $9.7(8-13)$ & 0.89 \\
Patients with $\geq 1$ polyp & & & \\
Patients with $\geq 1$ conventional adenoma & $189(55.4 \%)$ & $35(94.5 \%)$ & 0.001 \\
Males with $\geq 1$ conventional adenoma (ADR) & $123(36.1 \%)$ & $21(56.8 \%)$ & 0.014 \\
Females with $\geq 1$ conventional adenoma (ADR) & $55(38.5 \%)$ & $8(57.1 \%)$ & 0.17 \\
Patients with $\geq 1$ advanced neoplasm & $68(34.3 \%)$ & $13(56.5 \%)$ & 0.037 \\
Histology of lesions at second examination & $11(3.2 \%)$ & $2(5.4 \%)$ & 0.37 \\
Tubular adenoma & & & \\
Tubulovillous adenoma & $263(57.4 \%)$ & $37(44.0 \%)$ & \\
Hyperplastic polyp & $5(1.1 \%)$ & 0 & \\
Benign mucosa & $110(24.0 \%)$ & $36(42.9 \%)$ & \\
Sessile serrated polyp & $71(15.5 \%)$ & $10(11.9 \%)$ & \\
Inflammatory polyp & $7(1.5 \%)$ & $1(1.2 \%)$ & \\
\hline
\end{tabular}


Table 2: Number of subjects and interval between initial and second screening colonoscopies

\begin{tabular}{|c|c|c|}
\hline $\begin{array}{c}\text { Interval between screens } \\
\text { (years) }\end{array}$ & $\begin{array}{c}\text { Subjects without } \\
\text { polyps at baseline } \\
\text { exam }\end{array}$ & $\begin{array}{c}\text { Subjects with distal } \\
\text { hyperplastic polyps at baseline } \\
\text { exam }\end{array}$ \\
\hline 8 & 67 & 7 \\
\hline 9 & 43 & 9 \\
\hline 10 & 174 & 14 \\
\hline 11 & 33 & 3 \\
\hline 12 & 13 & 2 \\
\hline 13 & 8 & 2 \\
\hline 14 & 2 & 0 \\
\hline 15 & 1 & 0 \\
\hline
\end{tabular}


Table 3. Findings in 13 patients with advanced neoplasms at the second screening examinations

\begin{tabular}{|c|l|}
\hline Patient & \multicolumn{1}{c|}{ Finding } \\
\hline 1 & $\begin{array}{l}\text { 2mm and 6 mm tubulovillous adenomas in rectum and transverse colon } \\
\text { respectively }\end{array}$ \\
\hline 2 & $5 \mathrm{~mm}$ tubulovillous adenoma in cecum \\
\hline 3 & $6 \mathrm{~mm}$ tubular adenoma in sigmoid colon; high grade dysplasia \\
\hline 4 & $10 \mathrm{~mm}$ tubular adenoma in hepatic flexure \\
\hline 5 & $10 \mathrm{~mm}$ tubular adenoma in transverse colon \\
\hline 6 & $12 \mathrm{~mm}$ tubular adenoma in transverse colon \\
\hline 7 & $25 \mathrm{~mm}$ tubulovillous adenoma at ileo-cecal valve \\
\hline 8 & 25 tubulovillous adenoma in rectum \\
\hline 9 & $35 \mathrm{~mm}$ tubulovillous adenoma in ascending colon; high grade dysplasia \\
\hline 10 & $\begin{array}{l}10 \mathrm{~mm} \text { sessile serrated polyp in ascending colon, 12 mm tubular adenoma in } \\
\text { ascending colon }\end{array}$ \\
\hline 11 & $12 \mathrm{~mm}$ sessile serrated polyp in ascending colon \\
\hline 12 & $12 \mathrm{~mm}$ sessile serrated polyp in transverse colon \\
\hline 13 & $30 \mathrm{~mm}$ sessile serrated polyp in ascending colon \\
\hline
\end{tabular}


References

1. Rex DK, Johnson DA, Anderson JC, et al. American College of Gastroenterology guidelines for colorectal cancer screening 2009. Am J Gastroenterol 2009;104:739-50.

2. Levin B, Lieberman DA, McFarland B, et al. Screening and surveillance for the early detection of colorectal cancer and adenomatous polyps, 2008: a joint guideline from the American Cancer Society, the US Multi-Society Task Force on Colorectal Cancer, and the American College of Radiology. CA: a cancer journal for clinicians 2008;58:130-60.

3. U.S. Preventive Services Task Force. Screening for colorectal cancer: U.S. Preventive Services Task Force recommendation statement. Ann Intern Med 2008;149:627-37.

4. Rex DK, Cummings OW, Helper DJ, et al. 5-year incidence of adenomas after negative colonoscopy in asymptomatic average-risk persons. Gastroenterology 1996;111:1178-81.

5. Imperiale TF, Glowinski EA, Lin-Cooper C, Larkin GN, Rogge JD, Ransohoff DF. Fiveyear risk of colorectal neoplasia after negative screening colonoscopy. N Engl J Med 2008;359:1218-24.

6. Brenner H, Chang-Claude J, Seiler CM, Hoffmeister M. Long-term risk of colorectal cancer after negative colonoscopy. J Clin Oncol 2011;29:3761-7.

7. Rex DK, Lehman GA, Ulbright TM, et al. Colonic neoplasia in asymptomatic persons with negative fecal occult blood tests: influence of age, gender, and family history. Am J Gastroenterol 1993;88:825-31.

8. Imperiale TF, Wagner DR, Lin CY, Larkin GN, Rogge JD, Ransohoff DF. Risk of advanced proximal neoplasms in asymptomatic adults according to the distal colorectal findings. N Engl J Med 2000;343:169-74.

9. Lieberman DA, Weiss DG, Bond JH, Ahnen DJ, Garewal H, Chejfec G. Use of colonoscopy to screen asymptomatic adults for colorectal cancer. Veterans Affairs Cooperative Study Group 380. N Engl J Med 2000;343:162-8.

10. Schoenfeld P, Cash B, Flood A, et al. Colonoscopic screening of average-risk women for colorectal neoplasia. N Engl J Med 2005;352:2061-8. 